\title{
Understanding the Use of Real Time Reverse Transcriptase-Polymerase Chain Reaction (rRT-PCR) For Covid-19 Diagnosis
}

\author{
Adesola O. Olalekan1,2*, Bamidele A. Iwalokun',3,4, Olutoyin C. Adekunle5, \\ Hussaini A. Makun4, Tatfeng Mirabeau6, Oluyemi Akinloye,2
}

${ }^{1}$ Molecular Diagnostics Research Laboratory, Department of Medical Laboratory Science, Faculty of Basic Medical Sciences, College of Medicine, University of Lagos, Idi-araba, Lagos

${ }^{2}$ Centre for Genomics of Non-communicable Diseases and Personalized Healthcare, University of Lagos

3Molecular Biology \& Biotechnology Department, Nigerian Institute of Medical Research, Lagos

${ }_{4}^{4}$ African Centre for Excellence for Mycotoxins and food Safety, Federal University of Technology, Niger State

5Department of Medical Microbiology and Parasitology, Ladoke Akintola University of Technology, Osogbo

${ }^{6}$ Department of Medical Laboratory Science, Niger Delta University.

*Correspondence should be addressed to Adesola O. Olalekan: adesolaolalekan@unilag.edu.ng

Received 6th July 2020; Revised 7th August 2020; Accepted 8th August 2020

(C) 2020 Olalekan et al. Licensee Pan African Journal of Life Sciences. This is an Open Access article distributed under the terms of the Creative commons Attribution License (https://creativecommons.org/licenses/BY/4.o), which permits unrestricted use, distribution, and reproduction in any medium, provided the original work is properly cited.

\begin{abstract}
Background: Adequate knowledge of real time Reverse Transcriptase-Polymerase Chain Reaction (rRT-PCR) is critical for accurate implementation of the assay, interpretation of results and reporting. This mini-review describes the principles, procedures, and level of development of rRT-PCR assays for the control of the COVID-19 pandemic.

Methods: A narrative review was carried out to describe the principles of rRT-PCR, provide an update on the landscape of rRT-PCR protocols and elucidate the process control involved in preanalytical, analytical and post-analytical stages of COVID-19 testing .

Review Findings: The rRT-PCR is currently considered to be the acceptable standard for confirming COVID-19 diagnosis based on SARS-CoV-2 RNA detection via conversion to cDNA and amplification of target genes in real time using sequence specific TaqMan ${ }^{\circledR}$ probes. Available evidence indicates that different rRT-PCR protocols varying in number and type of target genes within SARS-CoV-2 genome are currently available for validation and emergency use approval (EUA) in pandemic countries. A total of $1-$ 3 target genes, comprising the ORF1a, ORF1b, RNA dependent RNA polymerase (RdRp), Nucleoplasid protein gene (N), Spike glycoprotein gene (S) and Envelope protein gene (E) are detected by these protocols.

Conclusion: rRT-PCR remains the most sensitive method for confirming, monitoring and managing COVID-19 disease in the ongoing pandemic in all affected countries. The need for validation of every rRTPCR protocol prior to deployment for COVID-19 testing and research into the development of alternative testing protocols are strongly recommended
\end{abstract}

Keywords: COVID -19, rRT-PCR, SARS-CoV-2, biological samples, target genes 


\section{1.o INTRODUCTION}

Real-time reverse transcriptase polymerase chain reaction (rRT-PCR) is a form of PCR that is presently used to detect the presence of Severe acute respiratory syndrome coronavirus 2, (SARS-CoV-2), the causative agent of Coronavirus Disease 2019 (COVID-19) in human specimens such as oro-pharyngeal, nasopharyngeal, bronchoalveolar lavage (BAL) and bronchial washings, stool and sputum sample of infected patients [1]. The SARS-CoV-2 is a novel positive sense single stranded enveloped RNA virus first reported on January 7, 2020 in Wuhan, Hubei province China [2]. It is an RNA virus that survives and multiply in the infiltrated cells of its prey and uses its genetic code to arrange the cell of this victim so that it can be producing the coronavirus [3]. It is transmitted from human to human through respiratory droplets produced from coughs or sneezes. When it enters the human cell, it usually binds to the angiotensinconverting enzyme 2 receptor and causes mild to fatal disease conditions in humans [4]. This devastating adverse disease state warrants the need for prompt diagnosis to track down the virus and treat the victims. After the confirmation of the SARS-CoV-2 infection in China, humans have been the vehicle of transmission of infection because of international travels and this SARS$\mathrm{CoV}-2$ infection has affected every continent. The virus is very minute, therefore there is a need for accurate detection and isolation of patients for case management. The ideal molecular biology technique should amplify the SARS-CoV-2 RNA via reverse transcription, producing several copies making it possible for the identification of genes of interest, hence the choice of rRT-PCR [5].

The rRT-PCR is the choice nucleic acid amplification technique for prompt detection of the SARS-CoV-2 virus. The SARS-CoV-2 as an RNA virus will need to be reverse or transcribe to a DNA since DNA is the only genetic material that can be amplified into many copies and detected in the presence of an excited fluorophore emitting fluorescence. The rRT-PCR is highly sensitive and specific and an average testing time is approximately between 3 to 4 hours including RNA extraction. The rRTPCR has an advantage over other methods such as culturing which is more laborious, prone to contamination and time-wasting [6, 7]. For this COVID19 pandemic, different genes are targeted within the RNA genome of SARS-COV-2 and are explored by various countries for the isolation of SARS-CoV-2. China targets the ORF1ab and Nucleoprotein (N), Germany is using two markers, E gene from the virus envelope and the RdRP gene encoding the RNA dependent RNA polymerase marker, France uses two domains within RdRP and the United State of America target the three- domain within the nucleoprotein. Hong Kong uses three targets of ORF1b, nsp14 and N gene and Japan targeted multiple genes and spike protein [8]. In this mini-review, the principles behind the test, the components needed for the testing, samples for COVID-19 diagnosis, advantages and limitations of the test are discussed.

\subsection{PRINCIPLE OF THE RRT-PCR TEST}

The genomic RNA is reverse transcribed to complementary DNA (cDNA) in the presence of a reverse transcriptase. The resulting cDNA then serves as a template for the amplification of gene target. This is based on the chemistry of PCR with the addition of a fluorescent probe for the detection of amplified product all at the same time [9]. There are several platforms e.g Taqman ${ }^{\circledR}$ OpenArray ${ }^{\circledR}$, Dynamic Array ${ }^{\mathrm{TM}}$, or SmartChip by different manufacturers for this procedure, in which the nuclei acid amplification and the detection steps are all performed in the same closed vessel. When the primer and probe anneal to their respective loci prior to amplification of their target gene, the fluorescent reporter dye becomes excited and transfers fluorescent light by a mechanism called fluorescence resonance energy transfer (FRET) which is absorbed by the quencher dye at a specific distance from the reporter in the TaqMan probe [10]. This light is eventually emitted as a fluorescence at specific wavelength during amplification due to the 5'-3' exonuclease activity of the DNA polymerase. The intensity of fluorescence increases with amplification cycles and is directly proportional to the amount (or number of copies) of the target gene [5]. The cycle number at which the fluorescence intensity will be seen to be more than the background fluorescence and this is called the cycle threshold $(\mathrm{Ct})$. The higher the concentration of the SARS-CoV-2 (E, N, S, Orf1a\& Orf1a) cDNA, the higher the amplification fluorescens signal and the lower the Ct value as demonstrated in Figure 1.

\section{O THE LEVEL OF DEVELOPMENT OF RRT-PCR FOR SARS-COV-2 DETECTION IN BIOLOGICAL SAMPLES}

Following the availability of whole genome sequence data of the Wuhan SARS-CoV-2 strains, several rRT-PCR assays have been developed by various manufacturers as in vitro diagnostics (IVDs) in response to COVID-19 pandemic for disease prevention and control. The manufacturers of these are also partnering with the Foundation for Innovative New Diagnostics (FIND) for validation, documentation and dissemination of validation reports of their IVDs. Some of the IVDs have been granted emergency use authorization (EUA) approval in different COVID-19 pandemic countries. 


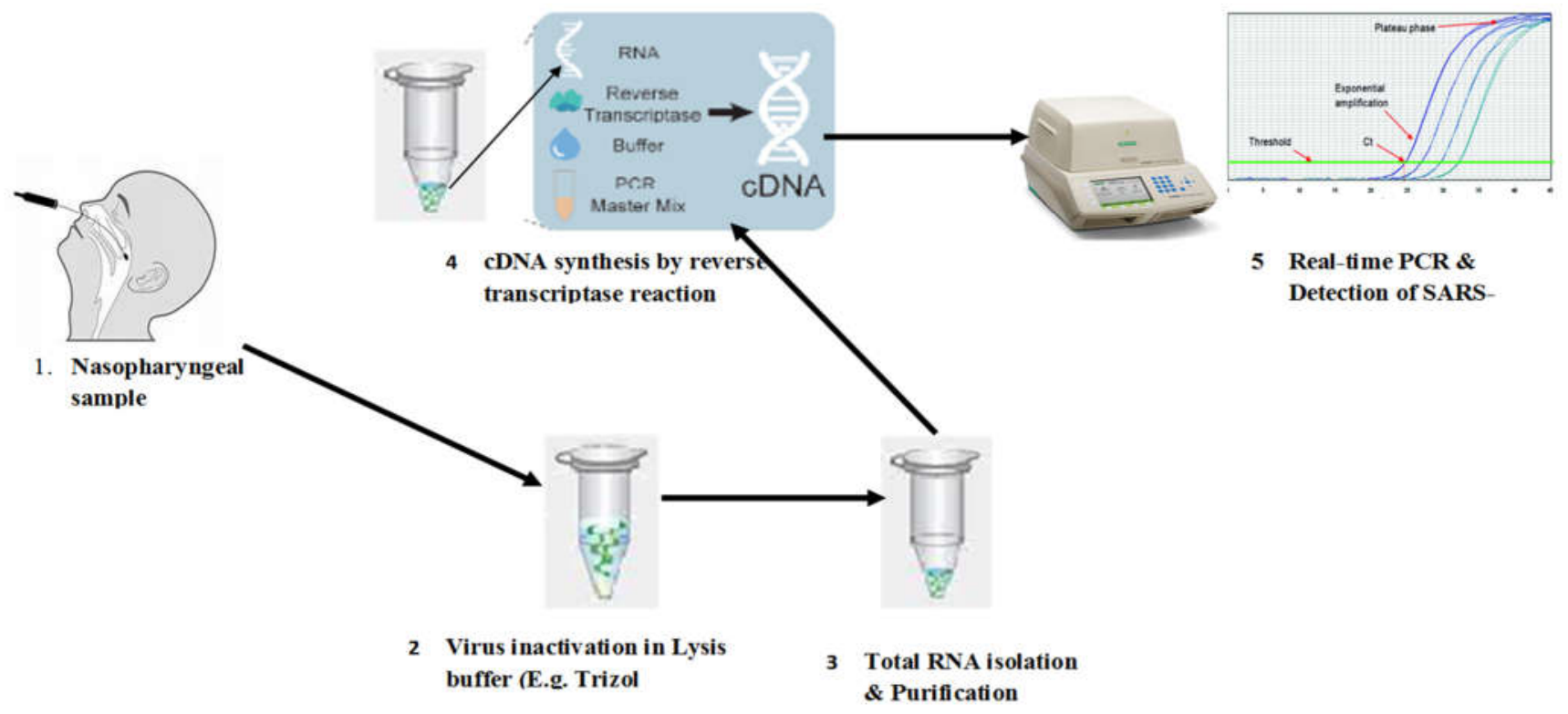

Figure 1. Schematic diagram illustrating the detection of SARS-CoV-2 RNA from nasopharyngeal sample.

Some of the platform popularly used for COVID-19 diagnosis can be found on the FIND website (www.finddx.org/covid-19/sarscov2-eval-molecular/ molecular-eval-results) [11], as represented in Table 1. All the platform used the same principles but what varies is the type of detection wavelength, the number of samples that can go in a run, the nucleic acid probe, the total reaction volume, the excitation, and the cycling condition [11]. The rRT-PCR always measure the target continuously at each cycle of the reaction in real-time as it is analyzing not at the end of the reaction. This complete cycle of the reaction is when the SARS-CoV-2 amplification is first detected.

\subsection{THE BIOLOGICAL SAMPLES FOR COVID-19 TESTING}

The biological samples for COVID-19 testing in various countries are based on the national guidelines in line with WHO recommendations. The biological samples include specimens from the lower respiratory tract (bronchoalveolar lavage (BAL), tracheal aspirate, and sputum) and specimens from the upper respiratory tract (e.g. nasal swab, oropharyngeal swab, nasopharyngeal swab and throat swab). Although, the lower respiratory tract specimens elicit higher sensitivity for COVID-19 diagnosis, sample collection is challenging because of the invasive procedure required for their collection by bronchoscopy (i.e. BAL and tracheal aspirates) and less frequent production of sputum by infected patients [1]. This has made oropharyngeal and nasopharyngeal specimens the most preferable specimens for COVID-19 testing in many countries of the world $[12,13]$. Eligibility for sample collection for COVID-19 testing at the beginning of the pandemic was based on epidemiological history (e.g. travel from pandemic countries such as China, USA, Germany, UK etc) and display of clinical symptoms such as fever, cough, fatigue, body pain and anosmia by a suspected person. Such a person is called person under investigation (PUI) [14], in addition community case transmission (CCT) was defined as person with cough and/or fever (or history of fever in the last 2 weeks with 1 or more of these symptoms Shivering /shaking (chills), Body pain, Headache, Sore throat, Recent loss of taste or smell, Difficulty in breathing/shortness of breath, Diarrhea/abdominal pain, Runny nose/catarrh and Fatigue (tiredness) by Nigeria Centre for Disease Control and prevention (NCDC) [15]. Sample collection plays an integral role in the diagnosis because the quality of samples collected determines the quality RNA isolated for rRT-PCR in terms of yield and stability [14]. Quality biological samples from PUI and CCT for COVID-19 diagnosis are ensured by collection of samples with more viable cellular component using appropriate viral transport medium under cold chain, and with good laboratory practice in handling and storage [16]. The latter is usually done at $-80^{\circ} \mathrm{C}$ prior to RNA isolation [16]. To improve isolation of SARS-CoV-2 genomic RNA for COVID-19 diagnosis from PUI and CCT, the use of a combination of nasopharyngeal and oropharyngeal swabs collected in the same tube has been 
Table 1. Platforms for COVID-19 Testing and Evaluation Results by Foundation for Innovative New Diagnostics (FIND)

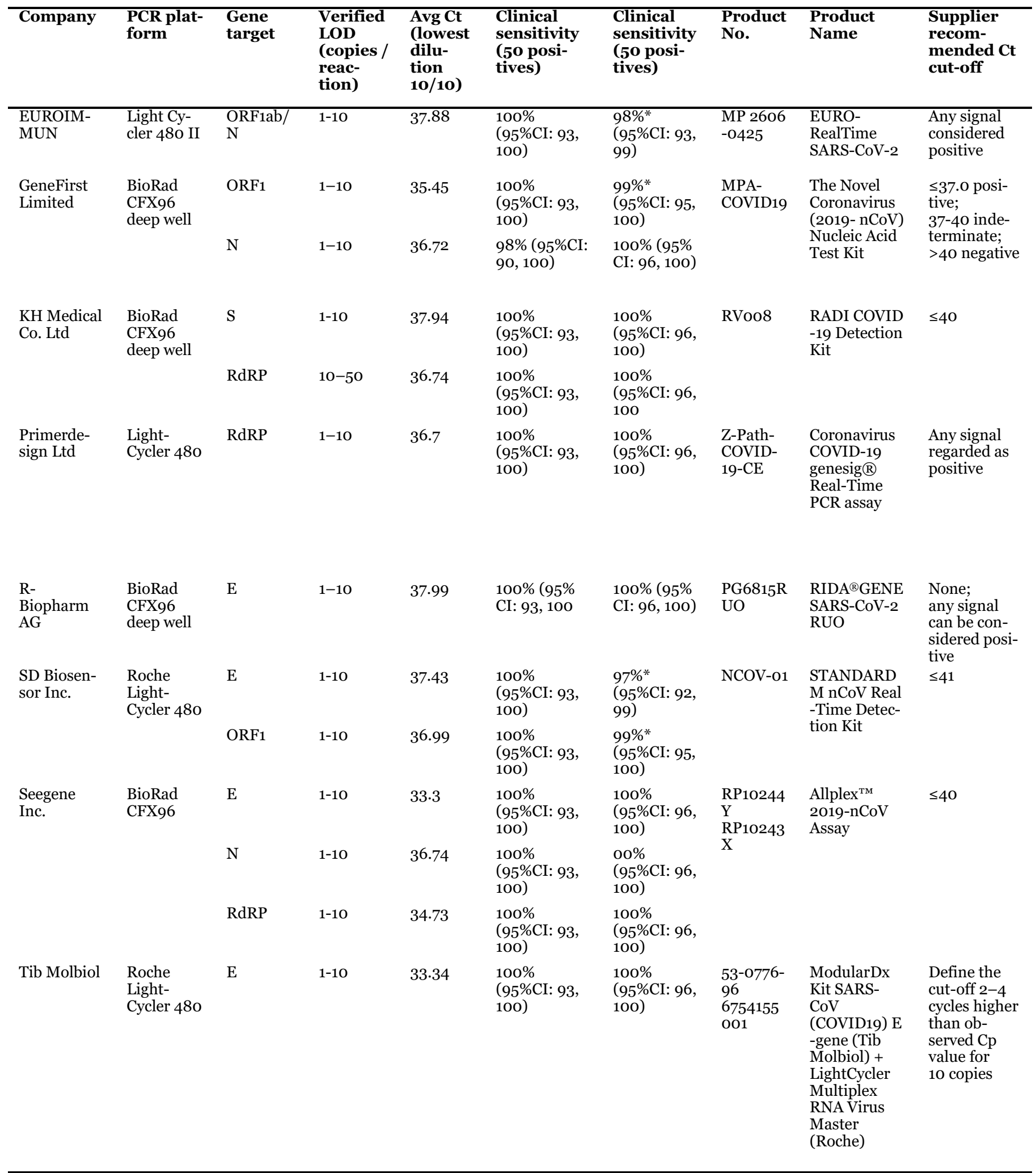

* Further investigation needed to determine if apparent false positives are truly false positives or whether they are due to a false negative reference standard result. Adopted from FIND website: www.finddx.org/covid-19/sarscov2-eval-molecular/molecular-eval-results/ last updated: 15 May, 2020. 
recommended coupled with repeated testing using different or the same type of biological samples at $1-3$ day intervals from a suspected person [8, 17-19]. This has been attributed to limited knowledge regarding appropriate time for SARS-CoV-2 virus detection in biological samples and the fact that that samples collected too early or too late may give false negative results $[18$, 19]. In Quality management system (QMS) perspective, the quality control of COVID-19 testing using the recommended biological samples is referred to as process control. This is divided into three stages: the preanalytical stage, the analytical stage, and the postanalytical stage. Performing all the activities in all the stages with the existing standard guidelines is pertinent for good results for patient's management [18]. This also entails appropriate selection of test subjects, biological specimens, transport media, diagnostic methods (i.e. rRT -PCR), interpretation of test results and biosafety $[18$, 20].
The collection and transportation of biological specimens for COVID-19 testing are usually done in a Viral Transport Medium (VTM) or Amies transport medium to preserve viability of SARS-CoV-2 infected cells and also for the safety of the health workers as well as averting community transmission. Other improvised VTM being used by laboratories include normal saline and phosphate buffered saline (PBS). However, using these improvised transport media require that such samples are stored at 2 $-8{ }^{\circ} \mathrm{C}$ for a very short $(<24 \mathrm{~h})$ period before processing [14]. Sample collected from a suspected case of COVID-19 must be package in triple layers and must follow the principles of transportation of biologicals in category $\mathrm{B}$ [14]. Apart from the upper and lower respiratory tract samples, other biological samples collected from suspected patients dead or alive for COVID-19 confirmatory test, routine and antibody testing include whole blood, urine, stool and biopsy samples (Table 2).

Table 2. Specimen Type, Collection Material and Storage and Transportation Condition

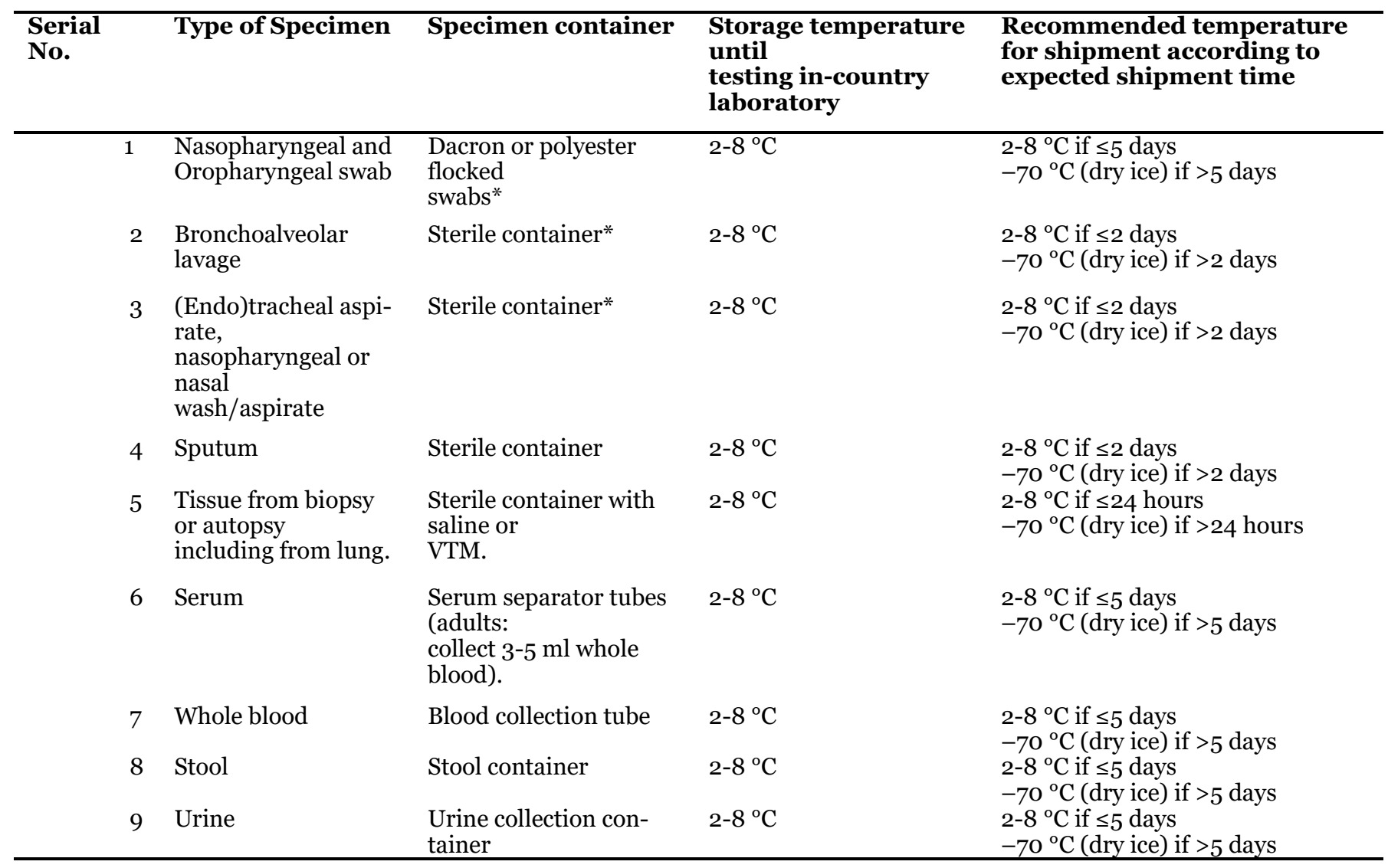

* For transport of samples for viral detection, use viral transport medium (VTM) containing antifungal and antibiotic supplements.

Avoid repeated freezing and thawing of specimens. If VTM is not available sterile saline may be used instead (in which case,

duration of sample storage at $2-8^{\circ} \mathrm{C}$ may be different from what is indicated above).

Adopted from /www.google.com/search?client=firefox-b-d\&q=FIND+samples+and+storage+for+COVID-19 
5.O BIOSAFETY REQUIREMENTS FOR COVID-19 TESTING

Frontline health workers collecting, handling, processing and conducting screening, confirmatory and routine tests for COVID-19 diagnosis from biological samples collected from suspected subjects must observe standard and transmission-based precautions. The precautionary measures include wearing of a complete Personal Protective Equipment (PPE), comprising long gown, head cover, recommended shoe, medical face mask with N95 respirator, face shield or compact goggles for eye protection, gloves and scrub suits [8]. Importantly the analytical procedures must be carried out in a class II biosafety cabinet or above. These procedures include aliquoting and inactivation of biological specimens, vortexing and heating of biological specimens in lysis buffer, spinning and heating of spin columns for elution of extracted RNA [7, 14]. After completion of RNA isolation, all infectious waste should be disposed according to environmental waste management guideline for COVID19 waste in every country, including Nigeria. The donned PPEs should be duffed carefully to avoid contamination of the body and hands of the health worker. The hands must be washed before and after contact with suspected patients and after removal of the PPEs. Hands should be washed with soap and water, followed by the use of hand sanitizer before leaving the laboratory.

\section{6.o RNA EXTRACTION}

The extraction of the RNA from any of the biological samples for COVID-19 diagnosis first involves inactivation of the sample. The best method to inactivate the SARS-CoV2 is using a chemical method. Here, a lysis buffer with viral inactivation property is used together with proteinase $\mathrm{K}$. The most common ones are guanidinium and Triton X100 , guanidinium isothiocyanate or guanidinium thiocyanate [21]. The principle of their action is to eliminate the virus infectivity, denature and disrupt proteins and envelope of SARS-CoV-2. The possibility of viral RNA degradation during sample inactivation is reduced by regulating the time of lysis, which is usually between $10-20$ minutes with biological samples and lysis buffer often mixed in volume ratio 1: 1 . At the completion of lysis, ethanol added to achieve complete inactivation of the virus. For rapid COVID-19 testing, RNA extraction kits from various manufacturers in different countries is made available for use. These kits also contain internal control RNA carrier to enhance RNA isolation even at low yield and silica membrane spin column for SAR-CoV-2 RNA binding followed by washing and elution. It is important to note that the carrier RNA should not be added directly to the sample but to lysis solution. This is to prevent the degradation of the carrier RNA and loss of signal of the internal control during amplification $[22,23]$.

\section{7.o REAL TIME RT-PCR PROCESS IN COVID -19 TESTING}

Real time RT-PCR is currently the most reliable method for confirming every COVID-19 case using respiratory samples in all countries experiencing COVID-19 outbreaks and surge in the number of cases as recommended by WHO. This stage of diagnosis entails the conversion of the isolated RNA to complimentary DNA (cDNA) in a reaction catalyzed by reverse transcriptase, followed by the amplification of the cDNA by DNA polymerase using sequence specific primers and probes. The rRT-PCR recommended for COVID-19 case confirmation is a one-step reaction in which both reverse transcriptase and DNA polymerase reactions occur in the same reaction tube. Resources of rRT-PCR include the availability of the whole genome sequences of SARS-CoV-2 index case in Wuhan, China (NC_045512) [24] and other countries, available freely in NCBI GenBank (https://www.ncbi.nlm.nih.gov/sars-cov2/) and The Global Initiative on Sharing avian Influenza Data (GISAID) (https://www.gisaid.org/epifluapplications/next-hcov-19-app/) databases. Primers and probes are designed based on the genome sequence map of a SAR-CoV-2 strain for a country (Figure 2) or by those provided by WHO and CDC (https://www.cdc.gov/ coronavirus/2019-ncov/lab/rt-pcr-panel-primer-

probes.html) [25]. (Table 3). Primers are designed using in silico primer designing algorithms such as Primer3 (http://primer3.wi.mit.edu) [26], and NCBI Primer blast [27]. The designed primers should also be optimized in silico using platforms at idtdna (https://sg.idtdna.com/ pages/tools/oligoanalyzer) and genomeucsc.edu (https:// genome.ucsc.edu/cgi-bin/hgPcr) [28] before their wet laboratory optimization. Generally, both the preformulated IVDs kits produced by different manufacturers for COVID-19 case confirmation (Table 1) and in-house rRT-PCR protocols recommended by CDC target 1- 3 genes within the SARS-CoV-2 genome (Table 1, Figure 2). A typical monoplex rRT-PCR reaction consists of forward and reverse primers of a target gene, a TaqMan ${ }^{\circledR}$ probe, a one-step enzyme mix consisting of a reverse transcriptase (and a DNA polymerase a reaction mix, containing oligo $\mathrm{dT}$, dNTPs and Magnesium in Tris buffer ( $\mathrm{pH}$ 8.0), an RNase free water and the isolated RNA as template. These components of rRT-PCR are added in appropriate concentrations as shown in Table 4. The primers and probes are usually synthesized by various manufacturers. The synthesized primers and probes are supplied to qualified laboratories in lyophilized form in labelled air-tight capped tubes. 


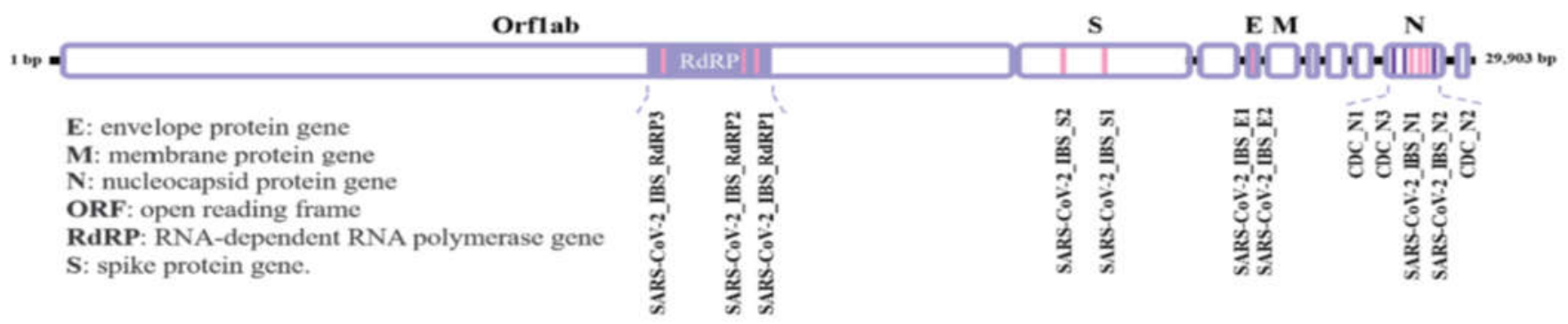

Figure 2. A Genome Map of SARS-CoV-2 Obtained from the Whole Genome Sequence of an Index Case Strain in South Korea, Showing the Location of the Designed Primers (including CDC designed primers) for the Detection of Specific SARS-CoV-2 Target Genes by rRT-PCR Assays [29]

Table 3. A List of Recommended Primers and Probes for the Detection of SARS-Cov-2 RNA Detection by Reverse Transcriptase Real Time PCR

\begin{tabular}{|c|c|c|c|c|}
\hline Name & Description & Oligonucleotide Sequence (5'>3') & Label1 & $\begin{array}{l}\text { Final } \\
\text { Conc. }\end{array}$ \\
\hline 2019-nCoV_N1-F & 2019-nCoV_N1 Forward Primer & GAC CCC AAA ATC AGC GAA AT & None & $500 n M$ \\
\hline 2019-nCoV_N1-R & 2019-nCoV_N1 Reverse Primer & TCT GGT TAC TGC CAG TTG AAT CTG & None & $500 n M$ \\
\hline 2019-nCoV_N1-P & 2019-nCoV_N1 Probe & FAM-ACC CCG CAT TAC GTT TGG TGG ACC-BHQ1 & $\begin{array}{l}\text { FAM, BHQ- } \\
1\end{array}$ & $125 \mathrm{nM}$ \\
\hline 2019-nCoV_N1-P & 2019-nCoV_N1 Probe & $\begin{array}{l}\text { FAM-ACC CCG CAT /ZEN/ TAC GTT TGG TGG ACC- } \\
\text { 3IABkFQ }\end{array}$ & $\begin{array}{l}\text { FAM, ZEN, } \\
\text { 3IABkFQ }\end{array}$ & $125 \mathrm{nM}$ \\
\hline 2019-nCoV_N2-F & 2019-nCoV_N2 Forward Primer & TTA CAA ACA TTG GCC GCA AA & None & $500 n M$ \\
\hline 2019-nCoV_N2-R & 2019-nCoV_N2 Reverse Primer & GCG CGA CAT TCC GAA GAA & None & $500 n M$ \\
\hline 2019-nCoV_N2-P & 2019-nCoV_N2 Probe & FAM-ACA ATT TGC CCC CAG CGC TTC AG-BHQ1 & FAM, BHQ- & $125 \mathrm{nM}$ \\
\hline 2019-nCoV_N2-P & 2019-nCoV_N2 Probe & FAM-ACA ATT TGC /ZEN/ CCC CAG CGC TTC AG-3IABkF & $\begin{array}{l}\text { FAM, ZEN, } \\
\text { 3IABkFQ }\end{array}$ & $125 \mathrm{nM}$ \\
\hline RdRP-F & RNAse P Forward Primer & AGA TTT GGA CCT GCG AGC G & None & $500 n M$ \\
\hline RdRP -R & RNAse P Reverse Primer & GAG CGG CTG TCT CCA CAA GT & None & $500 n M$ \\
\hline RdRP -P & RNAse P Probe & FAM - TTC TGA CCT GAA GGC TCT GCG CG - BHQ-1 & FAM, BHQ- & $125 \mathrm{nM}$ \\
\hline RdRP -P & RNAse P Probe & $\begin{array}{l}\text { FAM-TTC TGA CCT /ZEN/ GAA GGC TCT GCG CG- } \\
\text { 3IABkFQ }\end{array}$ & $\begin{array}{l}\text { FAM, ZEN, } \\
\text { 3IABkFQ }\end{array}$ & $125 \mathrm{nM}$ \\
\hline
\end{tabular}

*TaqMan $®$ probes are labeled at the 5 '-end with the reporter molecule 6-carboxyfluorescein (FAM) and with the quencher, Black Hole Quencher 1 (BHQ-1) (Biosearch Technologies, Inc., Novato, CA) at the $3^{\prime}$-end. TaqMan ${ }^{\circ}$ probes can also be labeled at the $5^{\prime}$-end with the reporter molecule 6carboxyfluorescein (FAM) and with a double quencher, ZEN ${ }^{\mathrm{TM}}$ Internal Quencher positioned between the ninth (9th) and tenth (10th) nucleotide base in the oligonucleotide sequence and Iowa Black ${ }^{\circledR} \mathrm{FQ}$ (3IABkFQ) located at the 3'-end (Integrated DNA Technologies, Coralville, IA) [25]

Table 4. A Monoplex Reaction Mix for rRT-PCR Reaction and in vitro Amplification

\begin{tabular}{lcl}
\hline Component & Volume (ml) & Final concentration \\
\hline RNase free water & 1.5 & $\mathrm{x} 1$ \\
@Reaction mix (x2) & 10.0 & $0.5 \mathrm{mM}$ \\
${ }^{*}$ Forward primer (10 mM) & 1.0 & $0.5 \mathrm{mM}$ \\
${ }^{*}$ Reverse primer (10 mM) & 1.0 & $0.25 \mathrm{mM}$ \\
${ }^{*}$ Probe (10 mM) & 0.5 & $\mathrm{x} 1$ \\
One step Enzyme Mix (x20) & 1.0 & \\
RNA Template & 5.0 & \\
Total reaction Volume & 20.0 & \\
\hline
\end{tabular}

The reaction mix is expected to contain between $3.5-4.0 \mathrm{mM} \mathrm{Mg}{ }^{2+}$ for an effective rRT-PCR; "The primer and TaqMan ${ }^{\circledR}$ probes constituents in the reaction mix are gene specific. 
Table 5. TaqMan ${ }^{\circledR}$ Probes Fluorophores Channels with their Excitation and Emission Wavelengths

\begin{tabular}{lll}
\hline $\begin{array}{l}\text { Fluorophore } \\
\text { Probe channel }\end{array}$ & $\begin{array}{l}\text { Excitation } \\
\text { wavelength, } \\
\text { nm }\end{array}$ & $\begin{array}{l}\text { Emission } \\
\text { wavelength, } \\
\text { nm }\end{array}$ \\
\hline FAM & 495 & 520 \\
VIC, HEX & 530 & 549 \\
ROX & 555 & 576 \\
Cy5 & 649 & 670 \\
\hline
\end{tabular}

*A dye is usually selected to fluoresce through a window or channel while detecting a gene target following amplification.

The probes are usually placed inside brown tubes and should not be exposed to light. Before opening the caps of the tubes, it is important to pulse spin to prevent loss of the lyophilized primers and probes. This is done prior reconstitution with RNase free water to prepare stock solutions of the supplied primers and probes. The preparation of stock solutions should be done in the dark to avoid loss of efficiency of fluorophores. For every primer or probe, stock solution is prepared by adding 10 times the concentration in nanomoles to prepare a $100 \mathrm{mM}$ stock solution or according to the specification of the manufacturer. To avoid repeated thawing and freezing at every use, the prepared stock solutions are usually diluted 10 -fold to $10 \mathrm{mM}$, which is used as working solutions and stored at $2-8{ }^{\circ} \mathrm{C}$ for routine rRT-PCR reactions (Table 4). Meanwhile the stock solutions should be stored at $-80^{\circ} \mathrm{C}$ to maintain their stability [16]. The next stage in the rRTPCR workflow is the amplification of primer targeted specific genes of SARS-CoV-2 by PCR and their detection by appropriate $\operatorname{TaqMan}^{\circledR}$ probes. A typical amplification condition comprises one cycle of reverse transcription step by the SuperscriptTMIII enzyme at $50^{\circ} \mathrm{C}$ for $10 \mathrm{~min}$, followed by a hot start step at $950 \mathrm{OC}$ for $1-3 \mathrm{~min}$ and finally 40-45 cycles of initial denaturation at $95^{\circ} \mathrm{C}$ for 10 seconds and primer annealing/extension by the Platinum Taq polymerase at $50-55^{\circ} \mathrm{C}$ for $30 \mathrm{sec}$. Each targeted gene in rRT-PCR is detected by a Taqman ${ }^{\circledR}$ probe based on fluorescence signal generation and accumulation due to a fluorophore at a particular wavelength within a set channel in a real time PCR machine. The different fluorophores used as reporters in TaqMan ${ }^{\circledR}$ include FAM with an excitation wavelength of $495 \mathrm{~nm}$ and emission wavelength of $520 \mathrm{~nm}$; HEX or VIC (530 nm, $549 \mathrm{~nm}$ ) ROX $(555 \mathrm{~nm}, 576 \mathrm{~nm})$ and Cy5 (649 nm, $670 \mathrm{~nm})$ (Table 5). Most probes for rRT-PCR have a common quencher called the black hole quencher (BHQ) to complete the probe chemistry and FRET technology prior to 5'-3' exonuclease activity of Platinum Taq polymerase during amplification. The real time PCR instruments recommended for COVID-19 case confirmation include ABI 7500 instrument (Applied biosystems, USA), Light cycler (ROCHE, USA), Biorad CFX96 (Biorad, USA) and QuantStudio 3 and 5 real time PCR system (Thermo Fisher, USA).

\section{8.o REAL TIME RT-PCR TEST RESULT INTER- PRETATIONS}

The design and analysis software of these instruments generate a threshold line above which a positive gene amplification is observed and this occurs at specific Ct value. For a positive result, each of the target genes is expected to produce an S-shaped amplification curve above the threshold line to suggest a positive test result. Since the emergence of the current COVID-19 pandemic, several in -house RT-PCR protocols and commercial RT-PCR IVD kits have been developed, made available through the FIND website (www.finddx.org/covid-19/pipeline) and have received European conformity label-in vitro diagnostics (CE-IVD) or (EUA in many countries. The interpretation of amplification outcome of each target gene is guided by $\mathrm{Ct}$ value, which may vary from one commercial kit to another. Generally, most kits interpret SARS-CoV-2 target genes with $\mathrm{Ct}$ values $<37$ is positive and $\mathrm{Ct}>38$ as negative. A Ct value between 37 and 38 is regarded as indeterminate. In many RT-PCR protocols for SARS-CoV -2 detection, the $\mathrm{E}$ gene detection is used as a screening test, which the detection of one or two genes (e.g. RdRP, $\mathrm{N}$, ORF1b,ORF1a) is used as a confirmatory test. For a test to be positive, the screening gene $\mathrm{E}$ and targeted one or two genes of rRT-PCR assay must be positive. In case of a two -confirmatory gene rRT-PCR platform, an indeterminate or inconclusive test also results when only one of the 2 genes is positive. In these rRT-PCR assays, the housekeeping gene that encoded the RNase $\mathrm{P}$ protein is codetected as an internal control to monitor amplification and also confirm the success of RNA isolation. A test result is negative if only the screening $\mathrm{E}$ gene is positive and the targeted confirmatory gene (s) is negative provided the negative internal control is negative. A test result with no internal control gene detection with the screening gene $\mathrm{E}$ is said to be invalid. A test result is also invalid if the screening test is negative and confirmatory test is positive (Table 6; Figure 3). However, several commercial RT-PCR IVD kits for SARS-CoV-2 have their specific results interpretation criteria for COVID-19 case identification. To guide the routine use of these commercial kits, it is important to verify their performance on gene by gene basis using in-house rRT-PCR protocol. The guidance for rRT-PCR performance metrics such as PCR efficiency, clinical sensitivity, clinical specificity and analytical sensitivity assessment is provided by the chief public health agency of every country. These agencies include NCDC, 
Olalekan et al Pan African Journal of Life Sciences (2020): 4(2): 86-97

Table 6. rRT-PCR Amplification Result Interpretation Scheme

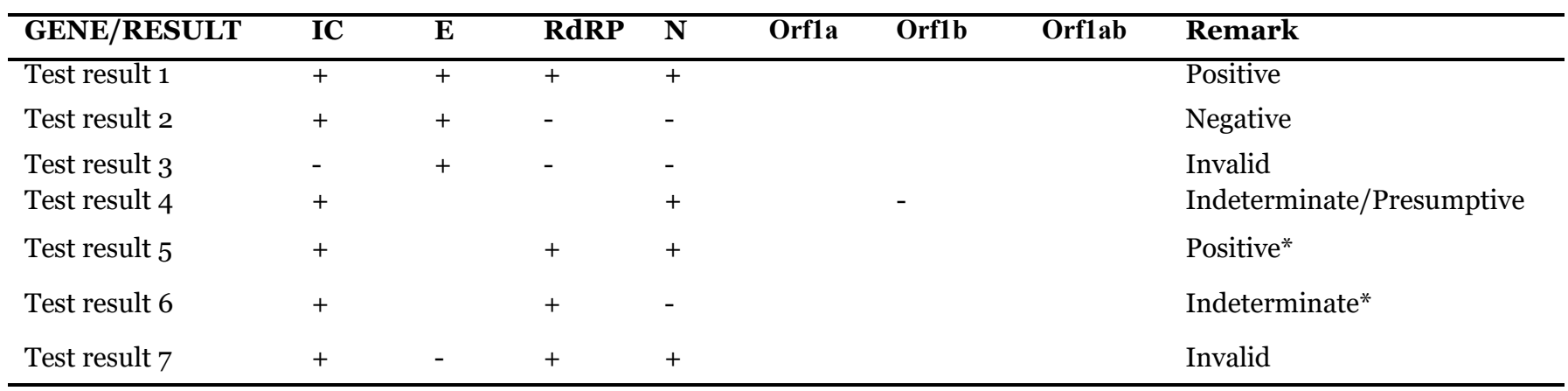

*Result interpretation is based on clinically positive samples by symptoms and chest tomography (CT) imaging results (e.g. Ground glass opacity)
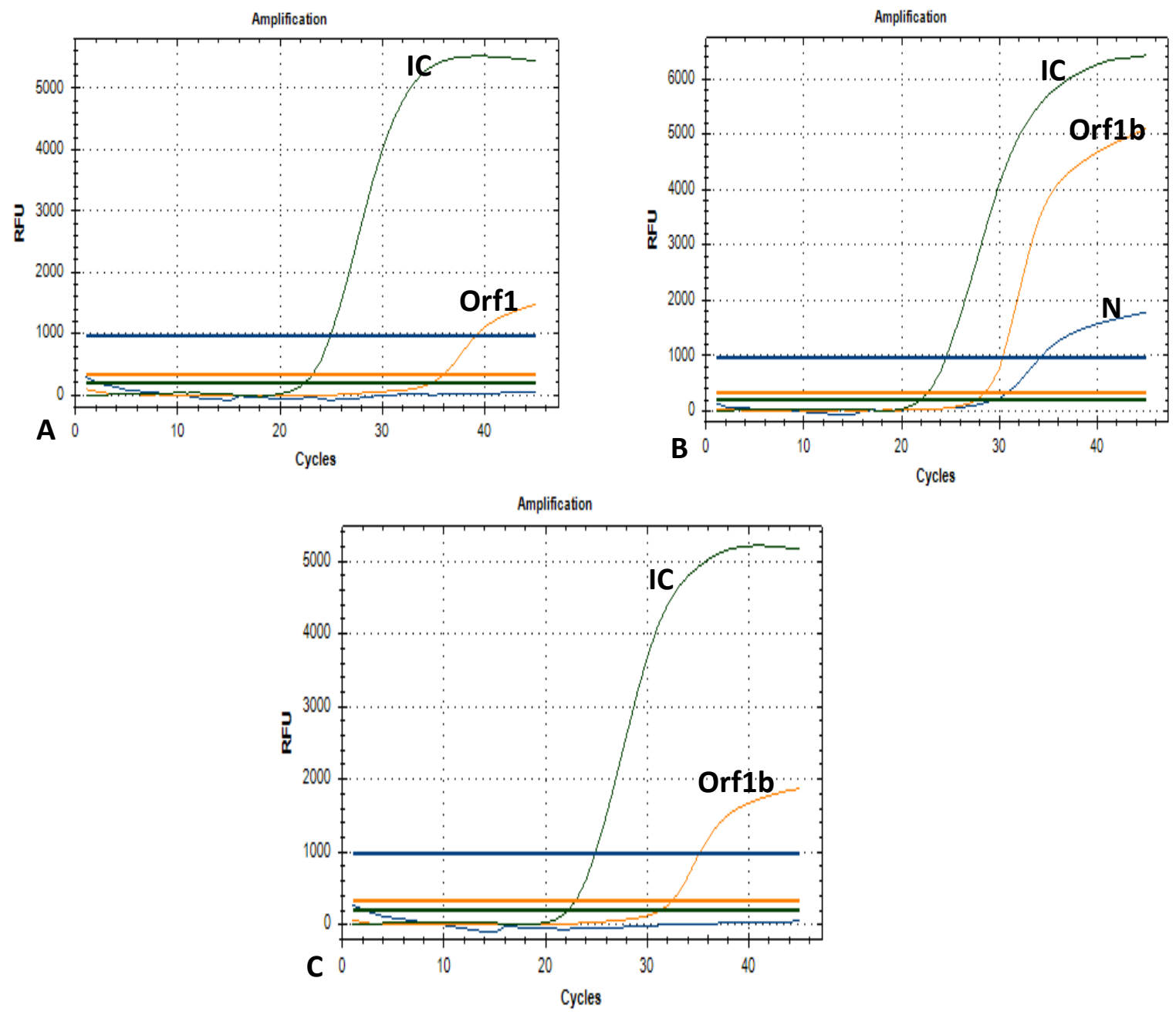

Figure 3. $\mathrm{rRT}$-PCR amplification curves for the detection of RNase P gene and SARS-CoV-2 orflb and N genes from nasopharyngeal samples of suspected patients. (unpublished data)

A. Negative results ( $\mathrm{Ct}$ value of orf1b $=39$ ); B. Positive Result; C. Indeterminate result (only orflb gene, $\mathrm{Ct}$ $=35.7 ; \mathrm{N}$ gene not detected). The RNase $\mathrm{P}$ gene represents the internal control (IC) 
Nigeria, Centre for Disease Control and Prevention (CDC), European Union Centre for Disease Control and Prevention (EU CDC) among others [30, 31]. Importantly, primer and probe design and optimization must be placed under a quality assurance system to enable their monitoring for high level performance and reliability. Such quality assurance systems include ISO9001 and ISO13485 [32]. To further ensure quality of result, every run of the rRT-PCR assay is also performed using positive control (e.g. live attenuated SARS-CoV-2 suspension with or without a clone or a synthetic RNA transcript of SARS$\mathrm{CoV}-2$ ) and a non-template negative control (e.g. RNase free water).

\subsection{LIMITATIONS OF RRT-PCR FOR SARS-COV- 2 TESTING}

Although rRT-PCR is currently the most sensitive method for routine confirmation of COVID-19 infection, it is still limited by its long turnaround time of $3-4$ hours even as a one-step method. It is also limited by the requirement for more expensive real time PCR system, high cost of the consumables (e.g. TaqMan ${ }^{\circledR}$ probe, One step enzyme mix, live attenuated SARS-CoV-2 and clone as positive control) and accessory instruments (e.g PCR hood). The need for trained laboratory scientists, requirement for constant electricity supply and regular equipment maintenance check to maintain the expected high level performance and reliability of the equipment may be a major challenge especially in developing countries. The rRT-PCR also require external quality control with a reference laboratory to determine concordance and discordance of positive and negative test results. The current rRT-PCR approach for detecting SARS-CoV-2 nucleic acid in biological samples is qualitative. On this basis, it cannot be used to quantify SARS-CoV-2 viral particles in biological samples and culture in permissible cells such as Vero cells. The performance of rRT-PCR can also be affected by sample source, timing of sampling, contamination of the consumables, poor handling and storage of biological specimens. Also, Poor handling and storage of isolated RNA samples, inadequacy of sample or low viral load, erroneous inactivation of samples, previous uptake of antiviral drugs before testing and poor annealing efficiency of the primer and probes due to mutations are other limiting factors [1, 32-35].

\subsection{ADVANTAGES OF rRT-PCR}

Despite the limitations of rRT-PCR for COVID-19 case confirmation. It is driving the current prevention and control in both developed and developing countries of the world because the protocols offer higher sensitivity, specificity and accuracy than antibody and antigen based- serological tests [36]. They can be performed using a broader spectrum of samples, which include respiratory samples (e.g. nasopharyngeal, oropharyngeal, throat swab, bronchio alveolar lavage/aspirate, sputum, trachea aspirates, stool, urine, serum, plasma, whole blood etc) compared to antibody-based tests (using serum, plasma, and whole blood only) [37], the detection of SARS-CoV-2 RNA in serum samples of convalescent patients has further provided new information regarding faecal-oral transmission of SARS-CoV-2 in the current COVID-19 pandemic [35]. The fact that SARS-CoV-2 RNA appears earlier than antibodies in human biological system makes it further advantageous for rRT-PCR to be used to monitor the trends in COVID-19 transmission, determine transmission dynamics, predict transmission surge and waves of secondary transmission. This is important for guiding health system preparedness for adequate response to protect public health. The rRT-PCR remains the most sensitive method for confirming, monitoring and managing COVID-19 disease in the ongoing pandemic in all affected countries. The need for validation of every rRT-PCR protocol prior to deployment for COVID-19 testing and research into the development of alternative and rapid diagnostics testing protocols are strongly recommended.

\section{Conflict of Interest}

The authors declare that there is no conflict of interest.

\section{Authors Contribution}

AOO conceived and designed the study, contributed to data collection, review of literature and manuscript writing; BAI contributed to study design and manuscript writing; OCA contributed to writing of manuscript; HAM, TM, OA contributed to data collection. All authors approved the final version of the manuscript

\section{References}

1. Yang Y, Yang M, Shen C, Wang F, Yuan J, Li J, et al. Evaluating the accuracy of different respiratory specimens in the laboratory diagnosis and monitoring the viral shedding of 2019-nCoV infections. medRxiv; 2020. 02.11.20021493; doi: https://doi.org/10.1101/2020.02.11.2002149

2. Zhu N, Zhang D, Wang W, Li X, Yang B, Song J, et al. A Novel Coronavirus from Patients with Pneumonia in China, 2019. The New England journal of medicine. 2020;382 (8):727-33.

3. Astuti I, Ysrafil. Severe Acute Respiratory Syndrome Coronavirus 2 (SARS-CoV-2): An overview of viral structure and 
host response. Diabetes Metab Syndr. 2020;14(4):407-12.

4. Liu J, Liao X, Qian S, Yuan J, Wang F, Liu Y, et al. Community Transmission of Severe Acute Respiratory Syndrome Coronavirus 2, Shenzhen, China, 2020. Emerg Infect Dis. 2020;26(6):200239.

5. Espy MJ, Uhl JR, Sloan LM, Buckwalter SP, Jones MF, Vetter EA, et al. Real-time PCR in clinical microbiology: applications for routine laboratory testing. Clin Microbiol Rev. 2006;19(1):165-256.

6. Deepak S, Kottapalli K, Rakwal R, Oros G, Rangappa K, Iwahashi $\mathrm{H}$, et al. Real-Time PCR: Revolutionizing Detection and Expression Analysis of Genes. Curr Genomics. 2007;8(4):234-51.

7. Loeffelholz MJ, Tang YW. Laboratory diagnosis of emerging human coronavirus infections - the state of the art. Emerging microbes \& infections. 2020;9(1):747-56.

8. WHO. Coronavirus disease (COVID-19) technical guidance: Laboratory testing for 2019-nCoV in humans". www.who.int. Retrieved 6 March 2020. wwwwhoint Retrieved 6 April 2020

9. Higuchi R, Fockler C, Dollinger G, Watson R. Kinetic PCR Analysis: Real-time Monitoring of DNA Amplification Reactions. Bio/Technology. 1993;11(9):1026-30.

10. Lamas A, Franco CM, Regal P, Miranda PM, Vázquez B and Cepeda A. High-Throughput Platforms in Real-Time PCR and Applications, Polymerase Chain Reaction for Biomedical Applications, in Ali Samadikuchaksaraei, IntechOpen, 2016; DOI: 10.5772/65760.

11. FIND. SARS-CoV-2 Molecular Assay Evaluatio: Results. wwwfinddxorg/covid-19/sarscov2-eval-molecular/ molecular-eval-results/ last updated: 15 may 2020. May 2020.

12. Wang X, Tan L, Wang X, Liu W, Lu Y, Cheng L, et al. Comparison of nasopharyngeal and oropharyngeal swabs for SARS-CoV-2 detection in 353 patients received tests with both specimens simultaneously. International Journal of Infectious Diseases. 2020; 94:107-9.

13. Wang D, Hu B, Hu C, Zhu F, Liu X, Zhang J, et al. Clinical Characteristics of 138 Hospitalized Patients With 2019 Novel Coronavirus-Infected Pneumonia in Wuhan, China. JAMA. 2020;323(11):1061-9.

14. World Health Organization. (2020). Laboratory testing for coronavirus disease (COVID-19) in suspected human cases: interim guidance, 19 March 2020. World Health Organization

handle/10665/331329/WHO-COVID-19-laboratory-2020.4 -eng.pdf?sequence $=1 \&$ isAllowed $=\mathrm{y}$

15. Nigeria Centre for Disease Control and prevention (2020). Community case definition for coronavirus disease. NCDC. May $32020 \quad$ https://twitter.com/ncdcgov/ status/1256922177489813505?lang=en

16. Logan JMJ EK. An overview of real-time PCR platforms in: Edwards K, Logan J, Saunders N, editors Real-time PCR an essential guide Horizon Bioscience, Norfolk, United King- dom. 2004.; Google Scholar: pp. 13-29.

17. CDC. Interim guidelines for collecting, handling, and testing clinical specimens from persons for coronavirus disease 2019 (COVID-19). https://wwwcdcgov/coronavirus/2019nCoV/lab/guidelines-clinical-specimenshtml (Updated on March 21, 2020).

18. Wong ML, Medrano JF. Real-time PCR for mRNA quantitation. BioTechniques. 2005;39(1):75-85.

19. Carter LJ, Garner LV, Smoot JW, Li Y, Zhou Q, Saveson CJ, et al. Assay Techniques and Test Development for COVID19 Diagnosis. ACS Central Science. 2020;6(5):591-605.

20. Hong KH LS, Kim TS, et al. Guidelines for Laboratory Diagnosis of Coronavirus Disease 2019 (COVID-19) in Korea. Ann Lab Med 2020;40(5):351-60.

21. Scallan MF, Dempsey C, MacSharry J, O'Callaghan I, O'Connor PM, Horgan CP, et al. Validation of a Lysis Buffer Containing $4 \mathrm{M}$ Guanidinium Thiocyanate (GITC)/ Triton X-100 for Extraction of SARS-CoV-2 RNA for COVID-19 Testing: Comparison of Formulated Lysis Buffers Containing 4 to 6 M GITC, Roche External Lysis Buffer and Qiagen RTL Lysis Buffer. bioRxiv 2020.04.05.026435; doi: https://doi.org/10.1101/2020.04.05.026435

22. Eis-Hübinger AM, Hönemann M, Wenzel JJ, Berger A, Widera M, Schmidt B, et al. Ad hoc laboratory-based surveillance of SARS-CoV-2 by real-time RT-PCR using minipools of RNA prepared from routine respiratory samples. Journal of Clinical Virology. 2020; 127:104381

23. Chan JF, Yip CC, To KK, Tang TH, Wong SC, Leung KH, et al. Improved Molecular Diagnosis of COVID-19 by the Novel, Highly Sensitive and Specific COVID-19-RdRp/Hel Real -Time Reverse Transcription-PCR Assay Validated In Vitro and with Clinical Specimens. Journal of clinical microbiology. 2020;58(5): eo0310-20.

24. Wu F, Zhao S, Yu B, Chen YM, Wang W, Song ZG, et al. A new coronavirus associated with human respiratory disease in China. Nature. 2020;579(7798):265-9.

25. Centre for Disease control and Prevention (2000). Research Use Only 2019-Novel Coronavirus (2019-nCoV) Real-time RT-PCR Primers and Probes. CDC. Updated 6 June, 2020. https://www.cdc.gov/coronavirus/2019-ncov/ lab/rt-pcr-panel-primer-probes.html

26. Untergasser A, Cutcutache I, Koressaar T, Ye J, Faircloth BC, Remm M, et al. Primer3--new capabilities and interfaces. Nucleic acids research. 2012;40(15): e115.

27. Ye J, Coulouris G, Zaretskaya I, Cutcutache I, Rozen S, Madden TL. Primer-BLAST: a tool to design target-specific primers for polymerase chain reaction. BMC bioinformatics. 2012; 13:134.

28. Elkins KM. An in-silico DNA cloning experiment for the biochemistry laboratory. Biochem Mol Biol Educ. 2011;39 (3):211-215.

29. Won J, Lee S, Park M, Kim TY, Park, MG et al. Development of a Laboratory-safe and Low-cost Detection Protocol for SARS-CoV-2 of the Coronavirus Disease 2019 (COVID- 
19). Exp Neurobiol. 2020;29(2):107-119.

30. van Kasteren PB, van der Veer B, van den Brink S, Wijsman L, de Jonge J, van den Brandt A, et al. Comparison of seven commercial RT-PCR diagnostic kits for COVID-19. Journal of clinical virology: the official publication of the Pan American Society for Clinical Virology. 2020; 128:104412.

31. Wang X, Yao H, Xu X, Zhang P, Zhang M, Shao J, et al. Limits of Detection of Six Approved RT-PCR Kits for the Novel SARS-coronavirus-2 (SARS-CoV-2). Clinical chemistry. 2020;66(7):977-979. doi:10.1093/clinchem/hvaao99

32. He JL, Luo L, Luo ZD, Lyu JX, Ng MY, Shen XP, et al. Diagnostic performance between CT and initial real-time RTPCR for clinically suspected 2019 coronavirus disease (COVID-19) patients outside Wuhan, China. Respiratory medicine. 2020; 168:105980

33. Park M, Won J, Choi BY, Lee CJ. Optimization of primer sets and detection protocols for SARS-CoV-2 of coronavirus disease 2019 (COVID-19) using PCR and real-time PCR. Experimental \& molecular medicine. 52: 963-977

34. Wallace PS, MacKay WG. Quality in the molecular microbiology laboratory. Methods in molecular biology (Clifton, NJ). 2013; 943:49-79.

35. Xiao AT, Tong YX, Zhang S. False-negative of RT-PCR and prolonged nucleic acid conversion in COVID-19: Rather than recurrence. Journal of medical virology. 2020 doi:10.1002/jmv.25855

36. Wang P. Combination of serological total antibody and RTPCR test for detection of SARS-COV-2 infections. Journal of virological methods. 2020; 283: 113919.

37. Lisboa Bastos M, Tavaziva G, Abidi SK, Campbell JR, Haraoui LP, Johnston JC, et al. Diagnostic accuracy of serological tests for covid-19: systematic review and metaanalysis. BMJ (Clinical research ed). 2020; 370: m2516 